\title{
Eficiência de pastejo de capim-marandu submetido a diferentes ofertas de forragem
}

\author{
Gustavo José Braga ${ }^{(1)}$, Carlos Guilherme Silveira Pedreira( ${ }^{(2)}$, Valdo Rodrigues Herling ${ }^{(3)}$ \\ e Pedro Henrique de Cerqueira Luz ${ }^{(3)}$
}

\begin{abstract}
(1)Agência Paulista de Tecnologia dos Agronegócios, Pólo Regional de Desenvolvimento Tecnológico dos Agronegócios Centro-Oeste, Unidade de Pesquisa e Desenvolvimento de Brotas, Rua Sebastião Soares, s/no, Caixa Postal 9, CEP 17380-000 Brotas, SP. E-mail: gjbraga@aptaregional.sp.gov.br (2)Escola Superior de Agricultura Luiz de Queiroz, Dep. de Zootecnia, Caixa Postal 9, CEP 13418-900 Piracicaba, SP. E-mail: cgspedre@esalq.usp.br (3)Universidade de São Paulo, Fac. de Zootecnia e Engenharia de Alimentos, Dep. de Zootecnia, Av. Duque de Caxias-Norte, no 225, CEP 13535-900 Pirassununga, SP. E-mail: vrherlin@usp.br e phcerluz@usp.br
\end{abstract}

\begin{abstract}
Resumo - O objetivo deste trabalho foi avaliar a eficiência de pastejo, o desaparecimento de forragem e a variabilidade espacial do dossel em pastagens de capim-marandu sob diferentes ofertas de forragem em pastejo realizado com bovinos da raça Nelore, em Pirassununga, SP. O delineamento foi em blocos completos ao acaso e os tratamentos consistiram de 5, 10, 15 e $20 \mathrm{~kg}$ de massa de forragem por $100 \mathrm{~kg}$ de peso vivo (PV) por dia (\%), aplicados em lotação rotativa. A taxa de desaparecimento de forragem respondeu positivamente ao aumento da oferta de forragem, oscilando de 2,3 a 6,5 $\mathrm{kg}$ de forragem por $100 \mathrm{~kg}$ de PV por dia em 2003 e de 2,3 a 6,2 kg por $100 \mathrm{~kg}$ de PV por dia em 2004. O desaparecimento de forragem por área não diferiu em 2003 (média $=56 \mathrm{~kg} \mathrm{ha}^{-1}$ por dia), ao contrário de 2004, quando os maiores valores foram verificados na oferta de forragem de $20 \%$ (44 kg ha-1 por dia). A eficiência de pastejo diminuiu com o aumento da oferta de forragem, e chegou ao máximo de $64 \%$ em 2003 e 55\% em 2004 para a oferta de 5\%. O aumento da oferta acarreta aumento contínuo da taxa de desaparecimento de forragem, ao contrário da eficiência de pastejo que decresce exponencialmente.
\end{abstract}

Termos para indexação: Brachiaria brizantha, desaparecimento de forragem, lotação rotativa, perdas de forragem, acúmulo de forragem, variabilidade espacial.

\section{Grazing efficiency on marandu palisadegrass as affected by herbage allowance}

\begin{abstract}
The objective of this work was to evaluate grazing efficiency, herbage disappearance and spatial variability of the sward in Marandu palisadegrass pastures rotationally stocked by yearling Nelore heifers at four levels of herbage allowance, in Pirassununga, SP, Brazil. The experimental treatments were 5, 10, 15, and $20 \mathrm{~kg}$ dry matter per $100 \mathrm{~kg}$ live weight per day (\%), in a randomised blocks design. Herbage disappearance rate increased with rising herbage allowance, and wide-ranging from 2.3 to $6.5 \mathrm{~kg}$ DM per $100 \mathrm{~kg} \mathrm{LW}$ per day in 2003, and from 2.3 to $6.2 \mathrm{~kg}$ DM per $100 \mathrm{~kg}$ PV per day in 2004. Conversely, herbage disappearance per area differed among treatments only in 2004, and was highest at $20 \%$ of herbage allowance ( $44 \mathrm{~kg} \mathrm{ha}^{-1}$ per day). Grazing efficiency decreased with rising herbage allowance, averaged $64 \%$ in 2003 and 55\% in 2004 for 5\% of herbage allowance. The increasing herbage allowance shows as consequence the increase herbage disappearance rate and an exponentially decrease of grazing efficiency.
\end{abstract}

Index terms: Brachiaria brizantha, forage disappearance, rotational stocking, forage losses, forage accumulation, spatial variability.

\section{Introdução}

Oferta de forragem é definida como a relação instantânea entre massa de forragem e peso vivo animal (FGTC, 1992). A fim de aproximar seus valores de números que atendam melhor suas expectativas de aplicação, a oferta de forragem é comumente expressada por uma unidade de tempo (dia), modificando a definição original. Esse padrão é originado da analogia com a taxa diária de consumo de forragem (Sollenberger et al., 2005).
A influência da oferta de forragem sobre consumo e desempenho animal (Boval et al., 2000) atua junto ao seu impacto sobre a eficiência de pastejo (Jensen et al., 1990; Virkajärvi et al., 2002). Acima de determinada oferta (5\%), entretanto, a taxa de consumo permanece relativamente constante e não responde mais ao aumento da oferta (Hodgson, 1990). Por sua vez, a taxa de desaparecimento de forragem (TDF) varia devido às alterações na extensão da forragem perdida pelo pisoteio, principalmente em condições de baixa eficiência 
de pastejo (Corrêa \& Maraschin, 1994). Stuth et al. (1981) verificaram em pastagens de Cynodon dactylon e Panicum coloratum, que o aumento da oferta resultou em acréscimo linear da TDF.

Entre as gramíneas tropicais, o capim-marandu é dos mais cultivados no Brasil Central, e apesar disso, trabalhos sobre oferta de forragem e seus efeitos sobre intensidade de desfolhação são escassos. Em estudos com espécies forrageiras tropicais, a oferta de forragem que gera o máximo desempenho animal tem-se mostrado altamente variável, desde 6 até $35 \mathrm{~kg}$ por $100 \mathrm{~kg}$ de PV por dia (Adjei et al., 1980; Boval et al., 2000). Em pastagens de capimtanzânia (Panicum maximum, cultivar Tanzânia-1) submetidas a tratamentos de oferta de forragem $(3,7,11 \mathrm{e}$ $15 \mathrm{~kg}$ de lâminas foliares por $100 \mathrm{~kg}$ PV por dia), o máximo ganho de peso foi atingido na oferta estimada de $10 \%$ aproximadamente (Barbosa et al., 2006).

Quando o acúmulo de forragem supera a demanda, o comportamento ingestivo dos animais leva invariavelmente ao aparecimento de pontos superpastejados e pontos subpastejados (Hodgson, 1990), pois a massa de forragem média torna-se excessivamente alta e de baixo valor nutritivo, concentrando o pastejo nos locais de massa inferior ao da média da pastagem e aumentando a heterogeneidade do dossel (Cid \& Brizuela, 1998). Virkajärvi et al. (2002) demonstraram que a principal causa da queda na eficiência de pastejo com o aumento da oferta de forragem em pastagens de Phleum pratense L. e Festuca pratense Huds. foi a maior proporção de áreas não pastejadas, pois áreas pastejadas apresentaram altura de resíduo similar, portanto independentes da oferta.

$\mathrm{O}$ aumento da produção animal por área em pastagens requer diminuição da oferta de forragem com níveis de desempenho minimamente satisfatórios. Por sua vez, para a maximização do desempenho individual, o aumento da oferta proporciona a melhora do valor nutritivo da dieta, compensando, em parte, os efeitos da inevitável queda na eficiência de pastejo (Adjei et al., 1980). Esse conflito deve, portanto, ser gerido com base no conhecimento dos limites de uso da espécie forrageira e de acordo com as metas do sistema de produção.

O objetivo deste trabalho foi avaliar a eficiência de pastejo, a taxa de desaparecimento de forragem e a variabilidade espacial da vegetação em pastagens de capim-marandu sob efeito de oferta de forragem.

\section{Material e Métodos}

O experimento foi conduzido em área pertencente à Prefeitura do Campus Administrativo de Pirassununga, USP ( $21^{\circ} 59^{\prime} \mathrm{S}, 47^{\circ} 26^{\prime} \mathrm{W}$ e $634 \mathrm{~m}$ de altitude). O clima do local é subtropical do tipo Cwa (inverno seco, verão quente e chuvoso) segundo classificação climática de Köppen. A precipitação pluvial mensal e a temperatura média diária foram registradas pelo Posto Meteorológico da Academia da Força Aérea, localizado em Pirassununga, SP (Tabela 1).

O estudo foi realizado numa pastagem formada em 1997 com Brachiaria brizantha (Hochst ex A. Rich.) Stapf, cultivar Marandu. O solo da área é classificado como Latossolo Vermelho-Amarelo, textura argilosa, fase cerrado (Embrapa, 1999), com pH $\left(\mathrm{CaCl}_{2}\right) 5,3 \mathrm{e}$ concentração de $\mathrm{P}$ (resina) de $8,7 \mathrm{mg} \mathrm{dm}^{-3}$. As concentrações de $\mathrm{K}, \mathrm{Ca}$ e $\mathrm{Mg}$ medidas no início do experimento foram 1,3, 23,0 e 10,0 $\mathrm{mmol}_{\mathrm{c}} \mathrm{dm}^{-3}$, respectivamente, e a saturação por bases $(\mathrm{V})$, de $59 \%$. A correção do solo para aumentar a V para $70 \%$ foi realizada com calcário magnesiano em novembro de 2001.

Tabela 1. Precipitação pluvial mensal $(\mathrm{mm})$ e temperatura média diária $\left({ }^{\circ} \mathrm{C}\right)$ de Pirassununga, SP.

\begin{tabular}{|c|c|c|c|c|c|c|c|c|}
\hline \multirow[t]{2}{*}{$\overline{\text { Mês }}$} & \multicolumn{4}{|c|}{ Precipitação pluvial } & \multicolumn{4}{|c|}{ Temperatura média diária } \\
\hline & 2002 & 2003 & 2004 & Média $^{(1)}$ & 2002 & 2003 & 2004 & Média $^{(1)}$ \\
\hline Janeiro & 384 & 269 & 187 & 251 & 24,4 & 24,4 & 22,6 & 24,2 \\
\hline Fevereiro & 174 & 165 & 419 & 217 & 23,5 & 26,1 & 22,2 & 24,3 \\
\hline Março & 54 & 156 & 74 & 155 & 25,5 & 24,2 & 21,4 & 23,8 \\
\hline Abril & 7 & 56 & 86 & 46 & 24,4 & 22,5 & 20,7 & 21,8 \\
\hline Maio & 51 & 51 & 110 & 41 & 20,2 & 18,0 & 17,7 & 19,5 \\
\hline Junho & 0 & 15 & 16 & 37 & 19,4 & 18,9 & 16,8 & 18,3 \\
\hline Julho & 11 & 13 & - & 19 & 17,5 & 17,7 & - & 18,1 \\
\hline Agosto & 91 & 13 & - & 25 & 21,6 & 18,1 & - & 20,0 \\
\hline Setembro & 42 & 15 & - & 52 & 20,7 & 21,9 & - & 21,6 \\
\hline Outubro & 53 & 47 & - & 126 & 26,1 & 23,6 & - & 22,6 \\
\hline Novembro & 92 & 25 & - & 157 & 24,6 & 22,2 & - & 23,1 \\
\hline Dezembro & 172 & 196 & - & 217 & 25,2 & 23,7 & - & 23,6 \\
\hline
\end{tabular}

${ }^{(1)}$ Média histórica de 30 anos, Pirassununga, SP. 
Em outubro de 2002, o corte para uniformização da pastagem foi realizado com roçadeira mecânica a uma altura média de $20 \mathrm{~cm}$ do solo. Do primeiro para o segundo ano de avaliação, não foi realizada uniformização das unidades experimentais. Durante o período experimental, foram aplicados por ciclo de pastejo $50 \mathrm{~kg} \mathrm{ha}^{-1}$ de $\mathrm{N}$ na forma de uréia e $25 \mathrm{~kg} \mathrm{ha}^{-1}$ de $\mathrm{K}_{2} \mathrm{O}$ na forma de cloreto de potássio. Em outubro de 2002, após uniformização da pastagem, e em dezembro de 2003, após pastejo, foram aplicados $90 \mathrm{~kg} \mathrm{ha}^{-1} \mathrm{de}_{2} \mathrm{O}_{5}$ na forma de superfosfato simples.

Os tratamentos foram quatro ofertas de forragem diárias: $5,10,15$ e $20 \mathrm{~kg}$ de massa de forragem (MF) medida no pré-pastejo para cada $100 \mathrm{~kg}$ de peso vivo (\%), com ciclos de pastejo de 35 dias, sendo sete de ocupação e 28 de descanso. O cálculo da oferta de forragem não levou em consideração o acúmulo de forragem ocorrido durante os sete dias de pastejo. O delineamento experimental foi o de blocos completos casualizados com quatro repetições. A área de 25,5 ha foi dividida em 16 unidades experimentais de 1,59 ha, subdivididas em cinco piquetes ( $35 \times 90 \mathrm{~m}$ ), a fim de comportar o ciclo de pastejo. Os animais utilizados foram bovinos da raça Nelore (Bos taurus indicus L.) com peso médio inicial de $250 \mathrm{~kg}$ e cerca de 15 meses de idade. Em cada unidade experimental, animais traçadores, em número de quatro em 2003 e três em 2004, foram mantidos durante todo o período para avaliações de desempenho, e animais reguladores foram adicionados ou retirados no decorrer das avaliações para ajustar a taxa de lotação de acordo com a oferta estipulada. A pesagem dos animais foi realizada a cada ciclo de pastejo sob jejum de água e comida (16 horas). A estimativa da MF em 2003 foi realizada de maneira direta pelo corte da forragem no nível do solo, em três pontos de área igual a $1 \mathrm{~m}^{2}(1 \mathrm{x} 1 \mathrm{~m})$ e representativos da condição média do piquete, seguindo uma estimativa visual.A MF foi medida em apenas um dos cinco piquetes da unidade experimental, sendo este denominado piquete-controle.

Em 2004, a estimativa da MF foi realizada com prato ascendente (Ashgrove, Palmerston North, Nova Zelândia) de $35,5 \mathrm{~cm}$ de diâmetro e 480,2 $\mathrm{g}$ de massa em aproximadamente 50 pontos do piquete. A calibração entre leitura do prato e MF foi realizada ao longo de todo o período experimental em todos os tratamentos, tanto no pré como no pós-pastejo e no $14^{\circ}$ dia de rebrotação. Em cada calibração, foram escolhidos cinco pontos de $1 \mathrm{~m}^{2}$ de área $(1 \mathrm{x} 1 \mathrm{~m})$ e com MF contrastante. Após a realização de quatro leituras em cada ponto, a forragem foi cortada no nível do solo para pesagem e cálculo da matéria seca em estufa de circulação forçada de ar, a $65^{\circ} \mathrm{C}$ por 72 horas, para obter a massa em matéria seca. Curvas de regressão linear foram utilizadas e, quando possível, agrupadas para limitar o número de equações geradas.

Foram estudadas duas estações de pastejo, de 2 de dezembro de 2002 a 16 de março de 2003, e de cinco de janeiro de 2004 a 19 de abril de 2004, doravante designados como 2003 e 2004, respectivamente, e compreendendo três ciclos de pastejo cada. No intervalo das avaliações, durante o inverno e a primavera de 2003, a pastagem continuou sendo manejada nas mesmas ofertas de forragem, mas com períodos de descanso de 56 dias e 7 dias de ocupação. Durante esse período não foi realizada adubação da área experimental.

A taxa de desaparecimento de forragem foi calculada de acordo com a equação:

$\mathrm{TDF}=\left[\mathrm{MF}_{\text {pré }}+\left(\mathrm{TAF}_{\mathrm{p}}\right)-\mathrm{MF}_{\text {pós }}\right] / \mathrm{DL}$, em que TDF é a taxa de desaparecimento de forragem em $\mathrm{kg}$ por $100 \mathrm{~kg}$

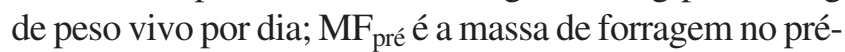
pastejo em $\mathrm{kg} \mathrm{ha}^{-1} ; \mathrm{TAF}_{\mathrm{p}}$ é a taxa média de acúmulo de forragem durante o pastejo em $\mathrm{kg} \mathrm{ha}^{-1} ; \mathrm{MF}_{\text {pós }}$ é a massa de forragem no pós-pastejo em $\mathrm{kg} \mathrm{ha}^{-1}$; DL é a densidade de lotação em $100 \mathrm{~kg}$ de peso vivo por hectare.

Com a finalidade de estimar o acúmulo de forragem ocorrido durante o período de ocupação, foram geradas curvas de regressão linear entre a MF medida na metade do período de descanso (14o dia de rebrotação) e a correspondente taxa de acúmulo de forragem do mesmo período, como descrito por Hirata (2000). Determinadas as curvas de regressão linear entre essas duas variáveis (Tabela 2), a média aritmética entre $\mathrm{MF}_{\text {pré } 1}$ e a $\mathrm{MF}_{\text {pós }} 1$ foi empregada como variável independente ( $\mathrm{x}$ ') para prever a variável dependente $\operatorname{TAF}_{\mathrm{p}}\left(\mathrm{y}^{\prime}\right)$, de acordo com equações do tipo $y^{\prime}=a+b x$ '.

Tabela 2. Equações de regressão desenvolvidas para a conversão da massa de forragem média do período de pastejo em taxa média de acúmulo de forragem no pastejo $\left(\mathrm{TAF}_{\mathrm{p}}, \mathrm{kg} \mathrm{ha}^{-1} \text { por dia }\right)^{(1)}$.

\begin{tabular}{lrcccc}
\hline Equações & OF & $\mathrm{R}^{2}$ & $\mathrm{CV}$ & EPM & $\mathrm{n}$ \\
\hline $\mathrm{TAF}=-21,72+0,0245 \mathrm{MF}_{14^{\circ}}$ & 5 & 0,84 & 10,7 & 2,18 & 14 \\
$\mathrm{TAF}=-5,22+0,0193 \mathrm{MF}_{14^{\circ}}$ & 10 & 0,79 & 14,1 & 3,22 & 15 \\
$\mathrm{TAF}=34,86+0,0040 \mathrm{MF}_{14^{\circ}}$ & 15 & 0,23 & 17,4 & 2,41 & 15 \\
TAF $=53,21+0,0043 \mathrm{MF}_{14^{\circ}}$ & 20 & 0,34 & 11,0 & 2,16 & 15 \\
\hline
\end{tabular}

(1) OF, oferta de forragem em \%; CV, coeficiente de variação em \%; EPM, erro-padrão da média em $\mathrm{kg} \mathrm{ha}^{-1}$ por dia; n, número de observações. 
A estimativa das perdas de forragem ocorridas durante o período de ocupação foi realizada de maneira indireta, baseada no trabalho de Stuth et al. (1981). Para isso, foi fixada uma taxa de consumo diária de $1,7 \%$ do peso vivo, (Oliveira et al., 2004). A forragem desaparecida, descontado o consumo estimado de $1,7 \mathrm{~kg}$ por $100 \mathrm{~kg}$ de PV por dia, foi admitida como perda (P). Dessa maneira, as perdas de forragem e o consumo foram calculados de acordo com as equações:

$\mathrm{P}=[(\mathrm{TDF}-1,7) 100 / \mathrm{TDF}] / 100$ e $\mathrm{C}=1,7 \mathrm{TL}$, em que $\mathrm{P}$ é a fração da forragem perdida no pastejo (\%); C é o consumo de forragem em $\mathrm{kg} \mathrm{ha}^{-1}$ por dia; TL é a taxa de lotação em $100 \mathrm{~kg} \mathrm{ha}^{-1}$ de PV.

A eficiência de pastejo foi calculada como a proporção da forragem que desapareceu no pastejo, descontando-se as perdas, em relação ao total de forragem acumulada no período anterior (Scarnecchia, 1988):

$\mathrm{EP}=[\mathrm{DF}(1-\mathrm{P}) / \mathrm{AF}] 100$, em que EP é a eficiência de pastejo em porcentagem; DF é o desaparecimento de forragem em $\mathrm{kg} \mathrm{ha}^{-1}$; AF é o acúmulo de forragem considerando período de descanso e ocupação em $\mathrm{kg} \mathrm{ha}^{-1}$.

A altura do dossel foi medida no pré e pós-pastejo em cerca de 30 pontos do piquete-controle da unidade experimental. As leituras foram realizadas a cada quatro passos do amostrador, em duas linhas retas dispostas na diagonal de cada metade do piquete. $\mathrm{O}$ critério adotado na caracterização da altura foi a escolha do ponto mais alto alcançado pela maior parte das folhas, ou de colmos quando no pós-pastejo, evitando distúrbios no dossel. A avaliação da dispersão das medidas de altura obtidas em cada piquete foi realizada por meio do seu coeficiente de variação $(\mathrm{CV})$, e sua variação porcentual após o pastejo (VPCV) foi usada como índice da variabilidade espacial do dossel (Hirata, 2002).

A análise estatística foi realizada por meio do procedimento MIXED do SAS (SAS Institute, 1999). Os dados obtidos em cada pastejo foram agrupados em valores médios para cada ano de avaliação. Os dois anos foram analisados separadamente, haja vista que as épocas das avaliações não foram as mesmas. Os tratamentos de oferta de forragem foram comparados por contrastes ortogonais polinomiais. $\mathrm{Na}$ estimativa da MF, com o prato ascendente, e da taxa média diária de acúmulo de forragem durante o pastejo, foram geradas curvas de regressão linear com o procedimento GLM (SAS Instute, 1999). A comparação das curvas foi realizada por meio de análise de covariância.

\section{Resultados e Discussão}

A temperatura média do ar entre novembro de 2002 e abril de 2003 foi ligeiramente superior (em torno de $1^{\circ} \mathrm{C}$ ) à média histórica do Município de Pirassununga, SP, ao contrário do ano posterior em que a média foi inferior (em torno de $1^{\circ} \mathrm{C}$ ) (Tabela 1). A precipitação pluvial durante este período esteve próxima da observada na série histórica do local, com exceção de fevereiro de 2004, quando se verificou cerca de $200 \mathrm{~mm}$ de chuva acima do normal.

As regressões lineares entre MF e leitura do prato ascendente geradas em 2004 apresentaram ajuste significativo dos dados $(\mathrm{p}<0,01)$, com $\mathrm{R}^{2}$ das curvas variando de 0,54 a 0,96 e o erro-padrão da média de 152 a $317 \mathrm{~kg} \mathrm{ha}^{-1}$ de MF. Quanto ao ajuste entre taxa de acúmulo de forragem e a MF medida no $14^{\circ}$ dia de rebrotação (Tabela 2), as equações lineares apresentaram $\mathrm{R}^{2}$ variando de 0,23 a $0,84(\mathrm{p}<0,10)$. As equações geradas nos diferentes tratamentos de oferta de forragem possuem coeficiente angular (b) e intercepto (a) diferentes $(\mathrm{p}<0,05) \mathrm{e}$, portanto, não puderam ser agrupadas numa única curva. Em virtude de dificuldades práticas em se medir o acúmulo de forragem durante o período de pastejo, a técnica empregada para o seu cálculo facilitou a tarefa, pois evitou o uso de gaiolas de exclusão e os problemas derivados desta técnica (Parsons et al., 1988). $\mathrm{Na}$ lotação rotativa, o acúmulo de forragem ocorrido no local e no momento do pastejo poderia ser desprezado, desde que o tempo de pastejo fosse breve, o que não ocorreu, já que os sete dias de pastejo equivaleram a 1/5 da duração do ciclo de pastejo de 35 dias.

A taxa de desaparecimento de forragem (TDF) sofreu efeito da oferta de forragem, tanto em $2003(\mathrm{p}<0,0001)$ como em 2004 ( $p<0,0001)$. Em 2003, o efeito foi linear (Figura 1 A), e atingiu o mais alto valor para a oferta de $20 \%$ (6,5 $\mathrm{kg}$ por $100 \mathrm{~kg}$ de PV por dia), e o mais baixo para a oferta de $5 \%$ (2,3 kg por $100 \mathrm{~kg}$ de PV por dia). Em 2004, o efeito foi cúbico (Figura 1 B), resultado ocorrido devido ao aumento de apenas $0,4 \mathrm{~kg}$ de forragem por $100 \mathrm{~kg}$ de PV por dia entre as ofertas 10 e $15 \%$. Walles et al. (1999) verificaram em pastagens de azevém perene (Lolium perenne L.) e trevo-branco (Trifolium repens $\mathrm{L}$.) que para ofertas de forragem entre $3,8 \mathrm{e}$ $13,3 \%$, a TDF aumentou linearmente de 1,4 a 3,1 e de 1,9 a 3,7 kg por $100 \mathrm{~kg}$ de PV por dia nas duas condições avaliadas, baixa e alta MF, respectivamente. Stuth et al. (1981) verificaram, em pastagens de Cynodon 
dactylon e Panicum coloratum, que a variação na oferta, de $1 \mathrm{a} 35 \mathrm{~kg}$ por $100 \mathrm{~kg}$ de PV por dia causou efeito linear crescente sobre a TDF (variação de 0,4 a $9,7 \mathrm{~kg}$ por $100 \mathrm{~kg}$ de PV por dia). A despeito da diferença nas espécies avaliadas, ambos os trabalhos apresentaram resultados semelhantes ao deste estudo. A TDF foi sempre superior à taxa de consumo assumida $(1,7 \%)$, indicando que a forragem que desapareceu e não foi consumida foi perdida por pisoteio, deposição de fezes e morte de tecidos. De maneira análoga, as perdas foram crescentes com o aumento da oferta, variando em média de 25 a $74 \%$ da forragem que desapareceu (Figura 1). A TDF se aproximou da taxa de consumo de forragem na oferta mais baixa, resultado semelhante ao verificado por Stuth et al. (1981).

Quando calculado como desaparecimento de forragem por área, a oferta de forragem não influenciou o resultado em 2003 ( $p=0,2548)$, que foi em média de $56 \mathrm{~kg} \mathrm{ha}^{-1}$ por dia (Figura $2 \mathrm{~A}$ ). Em 2004, o efeito da oferta $(\mathrm{p}=0,0158)$ foi quadrático, com o desaparecimento decrescendo da oferta de $5 \%$ para a de $15 \%$, e aumentando para a de $20 \%$ (Figura 2 B).
O desaparecimento de forragem por área expressa diferenças na taxa de lotação entre os tratamentos, relação que contrabalançou o efeito da oferta, tornandoo menos intenso que o efeito sobre a TDF. Houve efeito da oferta sobre o consumo total de forragem em 2003 $(p=0,0001)$ e em $2004(p=0,0001)$. Em 2003, o efeito foi cúbico (Figura 2 A), e em 2004, o efeito foi quadrático (Figura 2 B). Corrêa \& Maraschin (1994) avaliaram o efeito da oferta de forragem no manejo de pastagens nativas do Rio Grande do Sul sob lotação contínua e reportaram aumento linear do desaparecimento de forragem no verão, variando de aproximadamente 8 a $14 \mathrm{~kg} \mathrm{ha}^{-1}$ por dia para ofertas de 4 a $16 \%$, respectivamente.

As perdas de forragem (desaparecimento - consumo) foram de 16, 37, 37 e $40 \mathrm{~kg} \mathrm{ha}^{-1}$ por dia, em 2003, e de $10,17,17$ e $32 \mathrm{~kg} \mathrm{ha}^{-1}$ por dia, em 2004, respectivamente, para as ofertas de 5, 10, 15 e $20 \%$. Os resultados foram muito inferiores aos encontrados por Quadros et al. (2002), que estudaram espécies do gênero Panicum, e contabilizaram 322 e $218 \mathrm{~kg} \mathrm{ha}^{-1}$ por dia para capimmombaça (Panicum maximum Jacq. cultivar Mombaça)

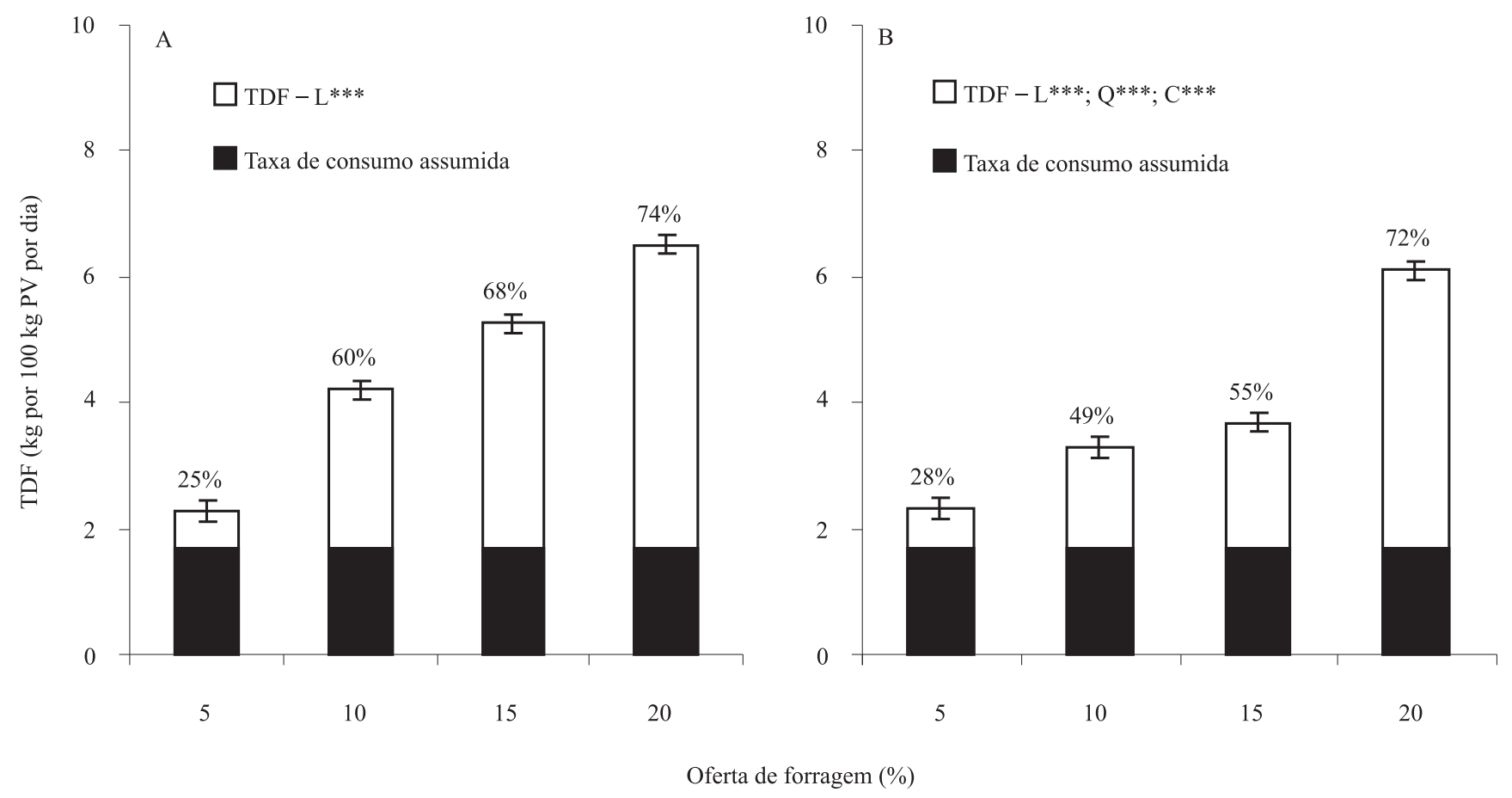

Figura 1. Taxa de desaparecimento de forragem (TDF) em pastagens de capim-marandu em resposta à oferta de forragem (OF) em 2003 (A) e 2004 (B). As barras verticais correspondem ao erro-padrão da média. Os valores porcentuais correspondem aos valores da TDF que excederam $1,7 \mathrm{~kg}$ por $100 \mathrm{~kg}$ de PV. Os contrastes ortogonais são indicados para o efeito de OF; L: efeito linear, Q: efeito quadrático e C: efeito cúbico. ***Significativo a $0,1 \%$ de probabilidade. 
e capim-tanzânia (Panicum maximum Jacq. cultivar Tanzânia-1), respectivamente. Os cálculos realizados neste trabalho levaram em consideração toda a unidade experimental e não só o piquete-controle, o que possibilita a discussão dos dados numa mesma base, quando comparados aos valores de acúmulo de forragem, e do mesmo modo em sua comparação com sistemas de pastejo sob lotação contínua. Isso equivale a descrever que os valores foram padronizados, considerando a taxa de lotação e não considerando a densidade de lotação. Os valores mais elevados observados a para oferta de $20 \%$ tanto em 2003 como em 2004 devem-se em parte ao intenso acamamento da forragem provocado pelo pisoteio dos animais.

Estudo conduzido em pastagem de capim-tanzânia demonstrou que a taxa de consumo de forragem aumentou de maneira quadrática com o aumento da oferta de forragem até atingir o ponto máximo $(2,3 \%)$ na oferta de $22 \%$ (Gontijo Neto et al., 2006). Os quatro tratamentos de oferta testados variaram de 6 a $24 \mathrm{~kg}$ de lâmina foliar por $100 \mathrm{~kg}$ de PV por dia. Quando corrigidos em termos de MF, essa amplitude equivaleu a 23 e $36 \%$, respectivamente, valores excepcionalmente altos, donde qualquer tentativa de extrapolação dos resultados para este estudo acarretaria em erro. A utilização da mesma taxa de consumo $(1,7 \%)$ justificase em razão de que, acima de 5\% (kg por $100 \mathrm{~kg}$ de PV por dia), não há significativa alteração no consumo individual (Hodgson, 1990). Se for assumido, por exemplo, uma taxa de consumo de 2,3\% para a oferta de $20 \%$, a variação na estimativa de perdas de forragem seria de nove pontos porcentuais para baixo (de 74 para 65\% em 2003 e de 72 para 63\% em 2004), variação pequena considerando os elevados valores observados. Neste trabalho, a utilização da mesma taxa de consumo assegurou que medidas de desempenho da pastagem fossem conhecidas e comparadas entre os diferentes tratamentos. Numa abordagem bem minuciosa, incluindo resultados sobre desempenho em ganho de peso individual, variações mínimas na taxa de consumo acrescidas do valor nutritivo da dieta não poderiam ser desprezados.

De maneira inversa ao ocorrido com as perdas, a eficiência de pastejo diminuiu com o aumento da oferta

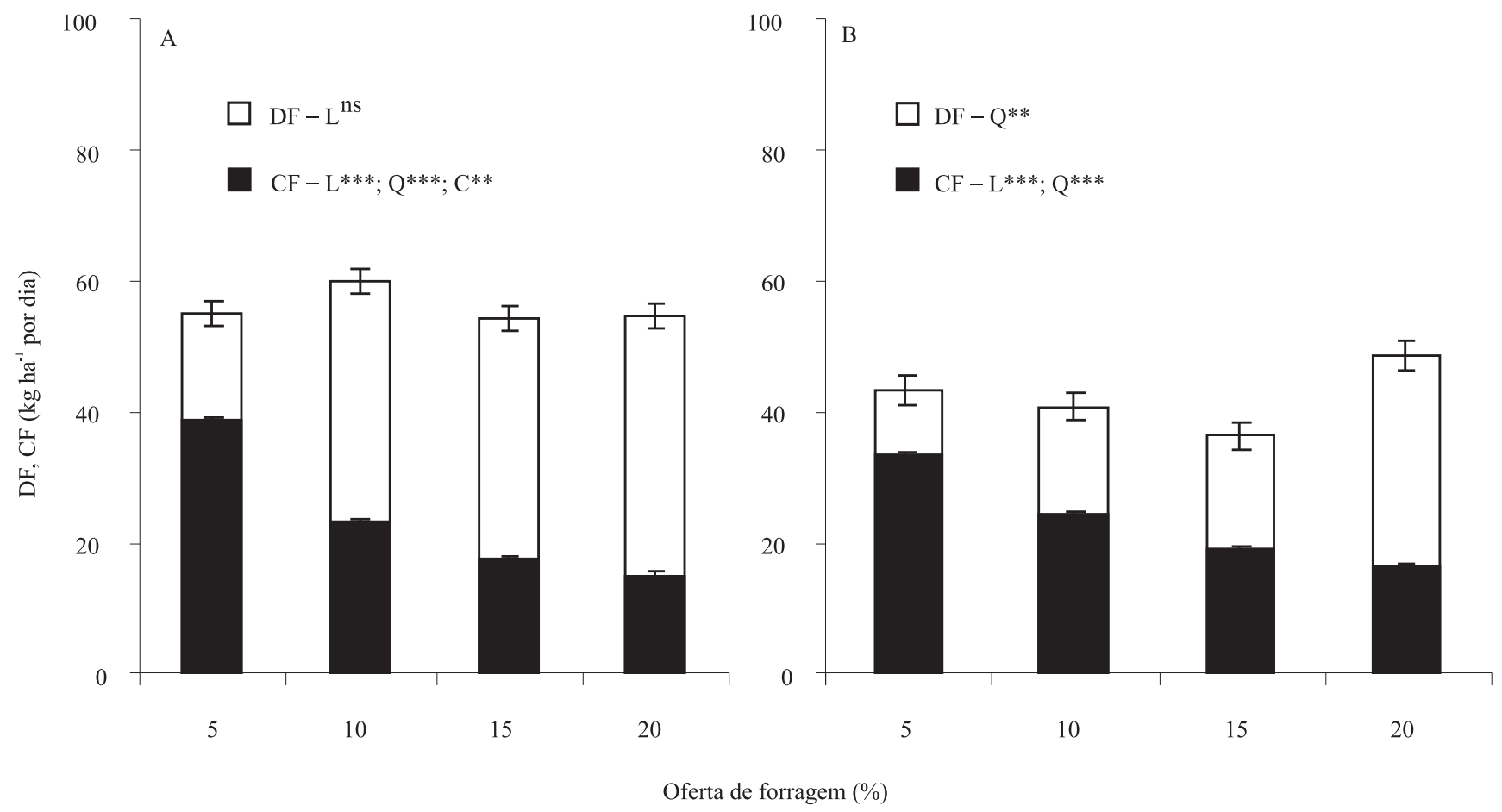

Figura 2. Desaparecimento de forragem (DF) e consumo de forragem (CF) por área em pastagens de capim-marandu em resposta à oferta de forragem (OF) em 2003 (A) e 2004 (B). As barras verticais correspondem ao erro-padrão da média. Os contrastes ortogonais são indicados para o efeito de OF; L: efeito linear; Q: efeito quadrático e C: efeito cúbico.

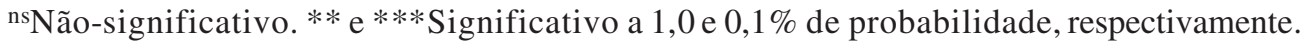


de forragem $(\mathrm{p}<0,0001)$. O efeito foi cúbico em 2003 e 2004 , diminuindo em taxas decrescentes com o aumento da oferta, condizente com uma queda exponencial (Figura 3). A eficiência de pastejo foi de 64, 33, $22 \mathrm{e}$ $17 \%$, em 2003, e 55, 30, 23 e $15 \%$ em 2004, respectivamente, para as ofertas de $5,10,15$ e $20 \%$. O aumento ocorrido da oferta de $10 \%$ para a de $5 \%$ foi de aproximadamente $100 \%$ tanto em 2003 quanto em

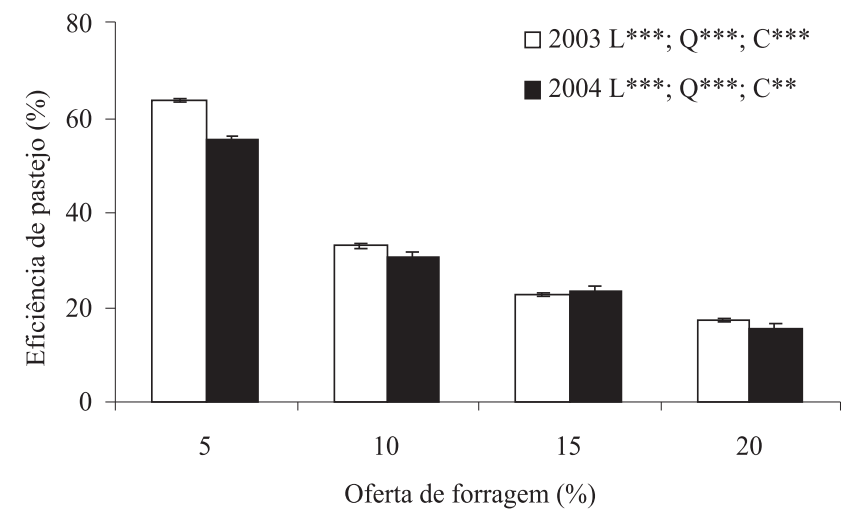

Figura 3. Eficiência de pastejo em pastagens de capimmarandu em resposta à oferta de forragem (OF) em 2003 e 2004. As barras verticais correspondem ao erro-padrão da média. Os contrastes ortogonais são indicados para o efeito de OF; L: efeito linear, Q: efeito quadrático e C: efeito cúbico. $* *$ e ***Significativo a 1,0 e $0,1 \%$ de probabilidade.

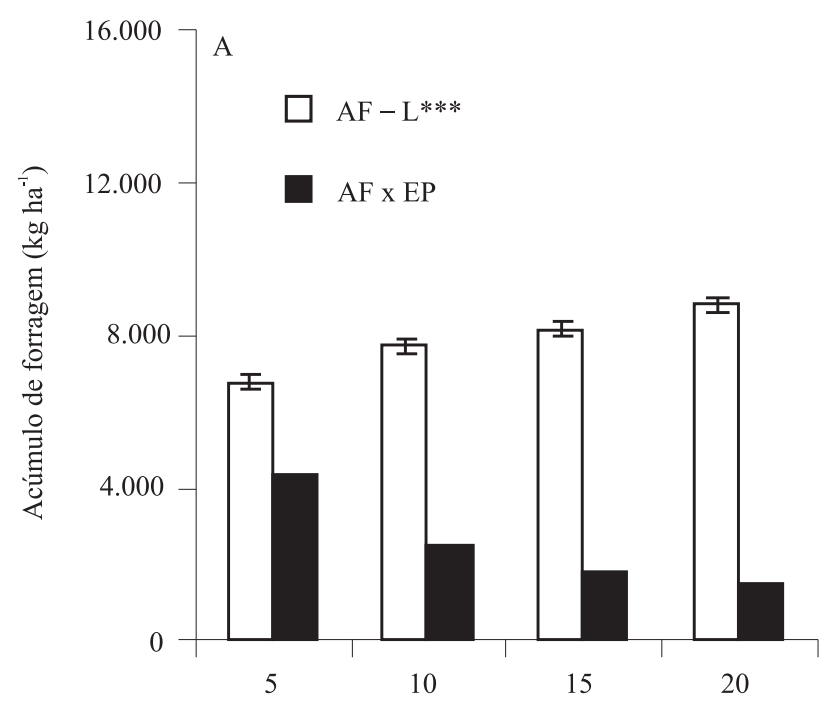

2004. Virkajärvi et al. (2002) verificaram, em pastagens consorciadas de Phleum pratense L. e Festuca pratense Huds., que sob ofertas variando de 3,6 a $5,1 \mathrm{~kg}$ de MF por $100 \mathrm{~kg}$ de PV por dia a eficiência de pastejo decresceu linearmente (68 a 54\%) com o aumento da oferta de forragem. A diminuição observada na oferta de 5\% de 2003 para 2004 pode ter sido causada pela maior dificuldade de preensão da forragem, em razão de mudanças no arranjo das plantas, visivelmente mais prostradas e próximas do solo (Braga et al., 2006). $\mathrm{O}$ acúmulo de forragem sofreu efeito da oferta em 2003 $(p=0,0005)$ e $2004(p<0,0001)$. Em ambos os anos, o efeito foi linear e crescente com o aumento da oferta (Figura 4). No entanto, o acúmulo de forragem efetivamente consumida ( $\mathrm{AF}$ x EP) diminuiu de maneira proporcional ao aumento do acúmulo de forragem.

Apesar da maior eficiência de pastejo na oferta de forragem de 5\%, estudo simultâneo conduzido na mesma área demonstrou que o maior ganho de peso por área ocorreu na oferta de $10 \%$, em virtude do desempenho animal mais elevado. $\mathrm{O}$ aumento da eficiência de pastejo nem sempre está associado à máxima produtividade animal, devido à menor eficiência de conversão da forragem em produto animal (Blaser, 1982). Assim, a maximização da eficiência de pastejo não deve ser almejada independentemente de outras considerações (Scarnecchia, 1988).

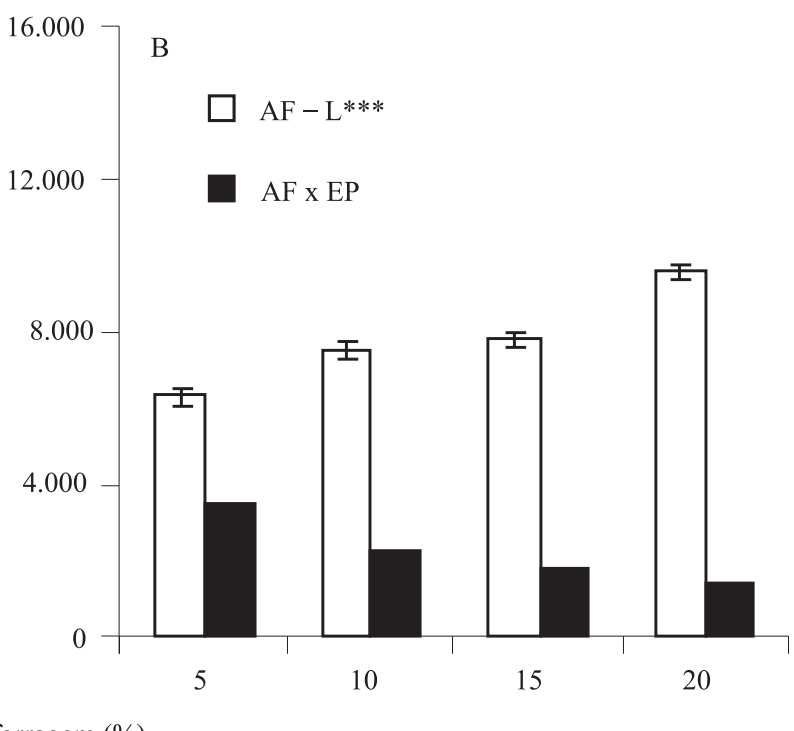

Figura 4. Acúmulo de forragem (AF) e acúmulo de forragem efetivamente consumida (AF x EP) em pastagens de capimmarandu em resposta à oferta de forragem (OF) em 2003 (A) e 2004 (B). As barras verticais correspondem ao erro-padrão da média. Os contrastes ortogonais são indicados para o efeito de OF; L: efeito linear, Q: efeito quadrático e C: efeito cúbico. *** Significativo a $0,1 \%$ de probabilidade. 
A oferta de forragem afetou $(p=0,0336)$ a variação porcentual do $\mathrm{CV}$ das medidas de altura do dossel em 2003, mas não em 2004 ( $\mathrm{p}=0,7391)$. O efeito de oferta foi quadrático em 2003, com valores mais baixos para oferta de 10\% (Figura 5). Com exceção da oferta de $10 \%$, houve aumento da variabilidade espacial do dossel após o pastejo. Na oferta de $10 \%$, a variação do CV com o pastejo foi negativa em 2003 e praticamente nula em 2004. Estudos de comportamento ingestivo indicaram que o hábito de pastejo leva a uma proporção constante entre profundidade do bocado e altura do dossel (Prache \& Peyraud, 2001). Estabelecida essa condição, uma variação mínima do $\mathrm{CV}$ das medidas de altura tenderia a ocorrer. O único tratamento que confirmou essa hipótese, tanto em 2003 quanto em 2004, foi a oferta de $10 \%$, já que os demais tiveram o CV aumentado após o pastejo.

Griffiths et al. (2003) relatam, quanto ao azevém perene (Lolium perenne L. cultivar Yatsyn), que o conceito da proporcionalidade constante foi inconsistente em dosséis maduros e de maior resistência ao cisalhamento. Provavelmente, a mesma situação ocorreu nos pontos de maior altura para as ofertas de forragem de 15 e $20 \%$, caracterizadas pela baixa eficiência de pastejo. Quanto à oferta de 20\%, durante o ciclo de pastejo II, em fevereiro de 2003, houve diminuição na altura média de 72 para $49 \mathrm{~cm}$ após o pastejo, ao passo que os valores máximos e mínimos diminuíram de 115

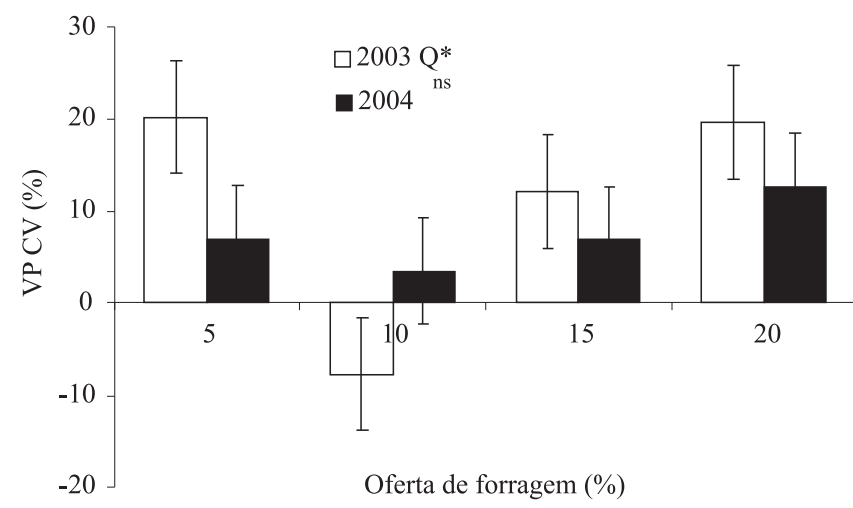

Figura 5. Variação porcentual do coeficiente de variação (VPCV) das medidas de altura média do dossel tomadas no pré e pós-pastejo em pastagens de capim-marandu em 2003 e 2004, sob efeito de oferta de forragem (OF). As barras verticais correspondem ao erro-padrão da média. Os contrastes ortogonais são indicados para o efeito de OF; L: efeito linear; Q: efeito quadrático e C: efeito cúbico. ${ }^{\text {ns} N a ̃ o-s i g n i f i c a t i v o . ~}$ *Significativo a $5 \%$ de probabilidade. para $85 \mathrm{~cm}$ e de 37 para $26 \mathrm{~cm}$, respectivamente. Isso evidencia a formação de um amplo mosaico na pastagem com pontos pastejados e pontos rejeitados. Na oferta de 5\%, também houve aumento do $\mathrm{CV}$, o que pode estar relacionado à maior deposição de fezes e pisoteio de plantas, causados pela maior taxa de lotação.

Por meio da apreciação visual dos piquetes pastejados, constatou-se que a variabilidade espacial na oferta de forragem de $5 \%$ foi dinâmica, ou seja, pontos rejeitados mudaram de localização ao longo dos ciclos de pastejo. Ao contrário, nas ofertas de 15 e $20 \%$, como os pontos de maior altura estiveram associados à presença de colmos maduros, a variabilidade espacial da vegetação foi estática, como verificado por Cid \& Brizuela (1998). Houve intenso acamamento das plantas nas pastagens submetidas à oferta de $20 \%$, fato que contribuiu para o aumento da variabilidade espacial e, ao mesmo tempo, para o aumento das perdas de forragem e da diminuição da eficiência de pastejo. Segundo Stuth et al. (1981), em pastagens sob ofertas mais baixas, ocorre uma condição mais homogênea com relação ao estádio de maturidade das plantas. Por sua vez, sob elevada oferta, a maturidade das plantas na pastagem se torna mais diversificada. Esta situação contribui para o aumento das perdas de forragem pelo aumento da quantidade de material senescente, além de reduzido crescimento tanto nas áreas subpastejadas como nas áreas superpastejadas.

Apesar do aumento linear do AF em função da oferta de forragem, ficou evidente o baixo aproveitamento da forragem nas ofertas de 15 e $20 \%$. Num primeiro momento, o aumento da área foliar residual é benéfico à rebrotação das plantas. No entanto, o contínuo aumento da sobra de forragem acarreta crescimento de colmos e amadurecimento das plantas, causando heterogeneidade no processo de desfolhação e, em casos extremos, acamamento do dossel (Dougherty \& Cornelius, 1999). Quando o manejo se mantêm em períodos de descanso fixos, parece razoável admitir que ofertas de forragem mais baixas, no caso 5 e $10 \%$, se ajustam melhor aos 28 dias de descanso utilizados neste experimento. Em ofertas mais elevadas, o aumento da freqüência de pastejo, deve ser considerado, sobretudo no uso de adubação nitrogenada. A eficiência de pastejo está intimamente relacionada à intensidade e frequiência do pastejo, e também ao consumo seletivo da forragem e à conseqüiente heterogeneidade do dossel, inevitáveis em certo sentido, mas que devem manter-se sob controle, a fim de evitar prejuízos ao crescimento das plantas e ao desempenho animal. 


\section{Conclusões}

1. O aumento da oferta de forragem apresenta como conseqüência aumento contínuo da taxa de desaparecimento de forragem, ao contrário da eficiência de pastejo que decresce exponencialmente.

2. A utilização das ofertas de forragem 15 e $20 \%$ não só diminui a eficiência de pastejo, como também provoca aumento da variabilidade espacial da vegetação.

\section{Agradecimentos}

À Fapesp, pelo financiamento do projeto de pesquisa e concessão de bolsa de doutorado ao primeiro autor.

\section{Referências}

ADJEI, M.B.; MISLEVY,P.; WARD, C.Y. Response of tropical grasses to stocking rate. Agronomy Journal, v.72, p.863-868, 1980.

BARBOSA, M.A.A. de F.; NASCIMENTO JUNIOR, D.; CECATO, U. Dinâmica da pastagem e desempenho de novilhos em pastagem de capim-tanzânia sob diferentes ofertas de forragem. Revista Brasileira de Zootecnia, v.35, p.1594-1600, 2006.

BLASER, R.E. Integrated pasture and animal management. Tropical Grasslands, v.16, p.9-24, 1982.

BOVAL, M.; CRUZ, P.; PEYRAUD, J.L.; PENNING, P.D. The effect of herbage allowance on daily intake by Creole heifers tethered on natural Dichanthium spp. pasture. Grass and Forage Science, v.55, p.201-208, 2000.

BRAGA, G.J.; PEDREIRA, C.G.S.; HERLING, V.R.; LUZ, P.H.C.; LIMA, C.G. Sward structure and herbage yield of rotationally stocked pastures of 'Marandu' Palisadegrass [Brachiaria brizantha (A. Rich.) Stapf] as affected by herbage allowance. Scientia Agricola, v.63, p.121-129, 2006.

CID, M.S.; BRIZUELA, M.A. Heterogeneity in tall fescue pastures created and sustained by cattle grazing. Journal of Range Management, v.51, p.644-649, 1998.

CÔRREA, F.L.; MARASCHIN, GE. Crescimento e desaparecimento de uma pastagem nativa sob diferentes níveis de oferta de forragem. Pesquisa Agropecuária Brasileira, v.29, p.1617-1623, 1994.

DOUGHERTY, C.T.; CORNELIUS, P.L. Intake of cattle offered normal and lodged tall fescue swards. Journal of Range Management, v.52, p.508-514, 1999.

EMBRAPA. Centro Nacional e Pesquisa de Solos. Sistema brasileiro de classificação de solos. Brasília: Embrapa-SPI; Rio de Janeiro: Embrapa-CNPS, 1999. 412p.

FORAGE AND GRAZING TERMINOLOGY COMMITTEE. Terminology for grazing lands and grazing animals. Journal of Production Agriculture, v.5, p.191-201, 1992.

GONTIJO NETO, M.M.; EUCLIDES, V.P.B.; NASCIMENTO JUNIOR; D.; MIRANDA, L.F.; FONSECA, D.M. da ; OLIVEIRA, M.P. de. Consumo e tempo diário de pastejo por novilhos Nelore em pastagem de capim-tanzânia sob diferentes ofertas de forragem. Revista Brasileira de Zootecnia, v.35, p.60-66, 2006.
GRIFFITHS, W.M.; HODGSON, J.; ARNOLD, G.C. The influence of sward canopy structure on foraging decisions by grazing cattle. II. Regulation of bite depth. Grass and Forage Science, v.58, p.125-137, 2003.

HIRATA, M. Herbage availability and utilization in small-scale patches in a bahia grass (Paspalum notatum) pasture under cattle grazing. Tropical Grasslands, v.36, p.13-23, 2002.

HIRATA, M. Quantifying spatial heterogeneity in herbage mass and consumption in pastures. Journal of Range Management, v.53, p.315-321, 2000.

HODGSON, J. Grazing management: science into practice. Essex: Longman Scientific and Technical, 1990. 203p.

JENSEN, H.P.; GILLEN, R.L.; MCCOLLUM, F.T. Effects of herbage allowance on defoliation patterns of tall-grass prairie. Journal of Range Management, v.43, p.401-406, 1990.

OLIVEIRA, L.O.F.; SALIBA, E.O.S.; RODRIGUEZ, N.M.; GONÇALVES, L.C.; BORGES, I.; AMARAL, T.B. Consumo e digestibilidade de novilhos Nelore sob pastagem suplementados com misturas múltiplas. Arquivo Brasileiro de Medicina Veterinária e Zootecnia, v.56, p.61-68, 2004.

PARSONS, A.J.; JOHNSON, I.R.; HARVEY, A. Use of a model to optimize the interactions between frequency and severity of intermittent defoliation and to provide a fundamental comparison of the continuous and intermittent defoliation of grass. Grass and Forage Science, v.43, p.49-59, 1988.

PRACHE, S.; PEYRAUD, J.L. Foraging behaviour and intake in temperate cultivated grasslands. In: GOMIDE, J.A.; MATTOS, W.R.S.; SILVA, S.C. da (Ed.). In: INTERNATIONAL GRASSLAND CONGRESS, 19 , 2001, São Pedro. Proceedings. Piracicaba: Fealq, 2001, p.309-319.

QUADROS, D.G.; RODRIGUES, L.R. de A.; FAVORETTO, V.; MALHEIROS, E.B.; HERLING, V.R.; RAMOS, A.K.B. Componentes da produção de forragem em pastagens dos capins Tanzânia e Mombaça adubadas com quatro doses de NPK. Revista Brasileira de Zootecnia, v.31, p.1333-1342, 2002.

SAS Institute. SAS/STAT user's guide: version 7.1. Cary: SAS, 1999.

SCARNECCHIA, D.L. Grazing, stocking, and production efficiencies in grazing research. Journal of Range Management, v.41, p.279281,1988 .

SOLLENBERGER, L.E.; MOORE, J.E.; ALLEN, V.G.; PEDREIRA, C.G.S. Reporting herbage allowance in grazing experiments. Crop Science, v.45, p.896-900, 2005.

STUTH, J.W.; KIRBY, D.R.; CHMIELEWSKI, R.E. Effect of herbage allowance on the efficiency of defoliation by the grazing animal. Grass and Forage Science, v.36, p.9-15, 1981.

VIRKAJÄRVI, P.; SAIRANEN, A.; NOUSIAINEN, J.I.; KHALILI, $H$. Effect of herbage allowance on pasture utilization, regrowth and milk yield of dairy cows in early, mid and late season. Animal Feed Science and Technology, v.97, p.23-40, 2002.

WALLES, W.J.; DOYLE, P.T.; STOCKDALE, C.R.; DELLOW, D.W. Effects of variations in herbage mass, allowance, and level of supplement on nutrient intake and milk production of dairy cows in spring and summer. Australian Journal of Experimental Agriculture, v.39, p.119-130, 1999. 